\title{
O Pensamento Geopolítico de Travassos, Golbery e Meira Mattos para a Amazônia
}

\author{
Felipe Garcia de Barros ${ }^{1}$
}

\begin{abstract}
Resumo: A região Amazônica tem uma centralidade para o Brasil e tem sido parte do desafio nacional não apenas integrá-la, mas também pensá-la. Neste contexto, três pensadores se destacam em suas ponderações acerca da geopolítica amazônica para o Brasil, América do Sul e para o Mundo. Cada um com suas contribuições particulares é isoladamente de grande valia, mas reunidos e comparados tem um valor inestimável. Sendo um dos primeiros, o Marechal Mário Travassos é leitor de Ratzel e trará suas ideias para aplicá-las no Brasil, sendo uma grande influência para Golbery e Meira Mattos nas décadas seguintes. Assim, o presente artigo busca apresentar e comparar a evolução da geopolítica da Amazônia sob esses três olhares, contando ainda com eventuais auxílios de modo a aprofundar a questão.
\end{abstract}

Palavras-chave:Geopolítica. Amazônia. Infraestrutura. Bacia Amazônica. América do Sul

\begin{abstract}
The Amazon region is central to Brazil and has been part of the national challenge not only to integrate it, but also to reflect on. In this context, three thinkers stand out in their reflections on Amazonian geopolitics for Brazil, South America and the world. Each with its particular contributions are alone of great value, but as they are compared the analysis becomes invaluable. One of the first Brazilian geopoliticians, Marshal Mário Travassos is a reader of Ratzel and will bring his ideas to apply them in Brazil, being a great influence for Golbery and Meira Mattos in the following decades. Thus, this article seeks to present and compare the evolution of Amazonian geopolitics from these three perspectives, also counting on possible aids in order to deepen the issue.
\end{abstract}

Keywords:Geopolitics. Amazon. Infrastructure. Amazon Basin. South America

\footnotetext{
${ }^{1}$ Doutorando pelo Programa de Pós Graduação em Economia Política Internacional
} 


\section{Introdução}

A região Amazônica representa metade do território nacional brasileiro e estende-se a oito outros Estados da América do Sul, soma-se a isso a casualidade do rio Amazonas e seus tributários que juntos representam a maior bacia hidrográfica do planeta. Esta imensa zona não passou despercebida pelos pensadores geopolíticos do Brasil e muitos deles contribuíram em seu estudo. Destes três se destacam por sua importância e este trabalho visa comparar suas abordagens acerca da região.

O Marechal Mário Travassos(1935) é o primeiro a surgir trazendo contribuições para discussão com seu conceito de dois antagonismos que formam a base para explicar o imperativo da projeção do Brasil sobre a região da bacia do Amazonas. Em seguida, será explorado o General Golbery do Couto e Silva (1981) que traz a ideia da ilha Amazônica que está alheia ao desenvolvimento que vinha ocorrendo no restante do país e projeta uma manobra concêntrica para "inundar a Amazônia de civilização". Por fim, o também General Carlos Meira Mattos (1980) que revoluciona a visão sobre a floresta com a proposta de Pan-Amazônia em que a floresta, a ser integrada, não está contida apenas no território nacional, mas em um espaço mais amplo com desafios em comum. Assim, dando seus primeiros passos a partir de setores militares, que olham tanto a questão nacional mais ampla no território sul-americano e mundial quanto em seus aspectos regionais, a Amazônia se torna um grande desafio à época e estende-se aos dias de hoje.

\section{Mário Travassos}

Travassos escreveu seu livro "Projeção Continental do Brasil" de 1935 no contexto da Revolução de 1930, quando se buscava interiorizar a economia e ocupar o sertão do território. Já no campo internacional a Argentina despontava por sua indústria e os Estados Unidos se faziam mais e mais presentes para além do caribe penetrando no continente. Ele foi profundamente influenciado 


\section{Universidade Federal Fluminense Instituto de Estudos Estratégicos}

pelo pensamento de Ratzel na Alemanha e será sua ideias serão basilares para os pensadores seguintes

A partir deste contexto, Travassos, lança sua visão para a geografia geral da América do Sul, buscando um sentido nesses movimentos políticos. Em sua análise, ele identifica quatro zonas que trariam efeitos opositivos entre si, ou como Travassos chama os "antagonismos" que pautaram a evolução política do continente e sua dinâmica regional e internacional. $O$ primeiro destes antagonismos, é causado pela cordilheira dos Andes que segrega a massa continental entre uma vertente pacífica e outra atlântica. Tal corte gera uma preponderância para a vertente atlântica por sua facilidade de acesso a centros dinâmicos do mundo, ao mesmo tempo em que a vertente pacífica será estreita e com menos terras. Por conseguinte, a vertente pacífica terá de vincular-se a um dos dois (outros) antagonismos existentes: o amazônico e o platino, sendo estes separados pelo planalto central brasileiro. Estes antagonismos, surgem pela massividade de suas hidrográficas e criam fatores homogeneizadores em suas respectivas regiões e, por conseguinte, tornam-se competidoras entre si.

Para Travassos a geografia é fundamental na organização de toda a dinâmica geopolítica, ela é o meio ou obstáculo, pelo qual se dá o trânsito entre essas zonas. Os rios surgem, desta forma, não sendo apenas barreiras e fronteiras, mas na verdade comunicadores que facilitam o intercâmbio e homogeneizam uma região.

Além dos rios, os Andes que aparentam uma intransponibilidade, também mostra zonas de penetração facilitada. As passagens naturais terrestres que conectam as regiões Atlântica e Pacífica pela cordilheira dos Andes são os chamados "Pasos" e "Nudos". Os Pasos são passagens naturais na cordilheira e os Nudos centros de dispersão de águas entre do lado Pacifico para o Atlântico, conforme figura abaixo. Eles trazem uma capacidade de mobilidade inter-regional já assumiram uma importância capital desde de os tempos pré-colombianos. 


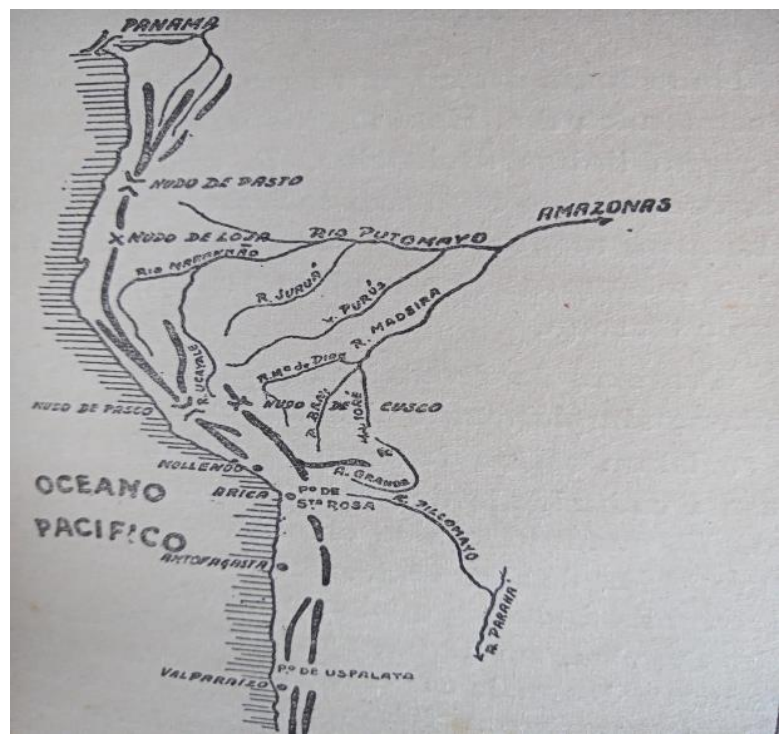

Mapa 1- Bacia Amazônica

Fonte: (Travassos, 1935, p.47).

Ainda conforme Travassos, as causalidades naturais podem ser neutralizadas ou ampliadas pela ação humana através da construção de infraestrutura de transporte concorrente ou complementar. Conforme será exposto mais a frente, a Argentina terá o ímpeto de potencializar a ação natural centrípeta da Bacia do Prata com uma infraestrutura complementar, enquanto o Brasil buscará anular este fenômeno no Prata com a construção de vias alternativas de transporte em seu território.

Surge assim o imperativo para que 0 Brasil se projete política e economicamente para o interior da América do Sul, a fim de garantir posições privilegiadas nas rotas continentais e negando a um rival tais posições. $O$ antagonismo Amazonas- Prata, exposto por Travassos (1935) tem uma natureza continental por conectar os interiores da América do Sul enquanto o AtlânticoPacífico os conectará ao restante do mundo.

É importante assim apontar que Travassos identifica a Bolívia como o Pivot Sul-Americano, ou em suas palavras ela contém o "triângulo estratégico", 


\section{Universidade Federal Fluminense Instituto de Estudos Estratégicos}

formado por Cochabamba-Sucre-Santa Cruz de La Sierra que dá acesso a todas as regiões. A Bolívia em seu altiplano guarda uma localização privilegiada no continente, tendo acesso a vertente pacífica, e as Bacias do Prata e Amazônica simultaneamente. Mesmo tendo tal privilégio por sua localização, a mesma também é a causa de uma forte instabilidade política. Tendo sido canibalizado por seus vizinhos ao longo de sua história e com a sua derrota pelo Chile se viu forçado a olhar para o ocidente. Além de ainda ser objeto de cobiça por sua centralidade.

O foco, então, será do antagonismo Amazonas- Prata que é separado a partir do altiplano boliviano a oeste e para leste pelo planalto central brasileiro. Algo que se deve salientar é a direção norte sul do rio da Prata enquanto o Amazonas é recebedor de águas ao norte e ao sul e tem seu curso do oeste para o leste, fato que apesar de a princípio ser um fator de repulsão entre as bacias também cria características particulares para cada. (TRAVASSOS, 1935)

Travassos enxerga a Argentina como o principal rival a ser superado nesta disputa. Em que os argentinos poderiam se valer da construção ferroviária para alcançar o heartland boliviano e de lá o Pacífico. Tal articulação não seria única e já contava com articulações por todas as capitais do cone sul, o que garantia a Argentina grande capacidade de se projetar na região e para além. No entanto, é colocado por Travassos que a região do Prata sofre uma desvantagem por sua verticalidade, o que torna a intervenção humana necessária consumar uma articulação mais completa. "Considerando a repulsão geográfica entre as bacias do Prata e Amazonas, sente-se bem o que traduz a política de comunicação platina como neutralização da má posição do Prata e como partido a tirar das incipiências da Amazônia." (TRAVASSOS, 1935, p.40). A Argentina por conta desta posição passa a tomar medidas para exacerbar o potencial centrípeto de sua bacia através de ferrovias que ligam o interior do continente a Buenos Aires seguindo o fluxo do rio da Prata, e por meio da Bolívia alcançar a Bacia Amazônica.

A Bacia Amazônica por outro lado possui naturalmente uma forma centrípeta, este fato é uma forma natural e dá ao deslocamento pela região Amazônica uma "espontaneidade". Ao sul pelo rio Madeira adentra a Bolívia pelo Mamoré, Beni e Madre de Dios; a oeste o Marañon segue pelo território peruano; 
a noroeste os rios Negro e Putamaio aproximam o Brasil da Colômbia e ao Norte o rio Branco que conecta ao Orinoco e por consequência ao Caribe. Travassos (1935) afirma que a posição central do Amazonas dá Brasil capacidade "homogeneizadora" sobre os demais territórios além de abrir ao Brasil capacidade de acessar o Pacífico através dos "Pasos" e "Nudos" dos Andes. Tais vantagens são ausentes no vertical rio da Prata.

Cabe ao Brasil tomar consciência dessa formidável realidade geográfica. Em suas mãos está o curso do Amazonas, o majestoso desfecho de todo drama econômico que se prepara nos bastidores do soberbo anfiteatro amazônico, o qual a largos passos vimos de percorrer, sobre a carta geográfica. (TRAVASSOS, 1935, p.130)

Entretanto, Travassos não tinha preocupação apenas com a expansão platina, mas também com a crescente presença americana oriunda do caribe ou "Mediterrâneo Americano". Além do recém criado canal do Panamá que é o grande eixo articulador dos americanos, dando fácil e rápido acesso a suas costas, por uma região de seu controle imediato. Deve-se assim, para o norte de nosso continente, onde tem uma barreira nas Guianas devido a presença europeia e geografia repulsiva, enquanto simultaneamente, existem as muito mais convidativas bacias do Orinoco e Madalena. A bacia do Orinoco possui acesso simples à bacia Amazônica por meio de canais naturais, enquanto a bacia de Madalena leva a importantes Pasos e Nudos na Colômbia. Tais fatos, somados ao fator centrípeto da Amazônia mostram a centralidade da bacia Amazônica não apenas para a América do Sul, mas para a inserção de potências estrangeiras em busca de recursos naturais como petróleo e a borracha.

Dada a importância avassaladoramente crescente do avião e do automóvel, sem dúvida nenhuma cabem à borracha e ao petróleo as referências que devem balizar o primeiro lanço às influências político-econômicas yankees em território sulamericano. A esses imperativos respondem o controle exercido pelos americanos sobre o petróleo da Venezuela, Colômbia e Peru e a atuação Ford na Amazônia. (TRAVASSOS, 1935, p.9899) 


\section{Universidade Federal Fluminense Instituto de Estudos Estratégicos}

Assim, ele reconhece que já nos anos 30 a "infiltração" americana é algo de peso, especialmente no Caribe e Andes, mas que o Brasil deve agir para garantir essas posições se valendo de sua localização para lançar sua influência nos vizinhos. Caso contrário, a mesma posição que dá privilégio ao Brasil servirá de passagem para seu rival. Pode-se assim perceber dois fatos que Travassos identifica acerca da região Amazônica. A primeira é a natural centralidade e capilaridade interiorana para as bordas através de uma colossal rede fluvial. A segunda é a centralidade da Amazônia nas duas grandes rivalidades brasileiras ao sul em seu antagonismo com o Prata e ao norte sofrendo a crescente pressão americana em busca de recursos naturais.

Ademais, é interessante notar em projetos mais recentes de integração, em particular os propostos por Darc Costa (2003) e pela Corporación Andina de Fomento (1998), a possibilidade de conjugar todas as principais bacias do continente por meio de obras. Duas em particular se destacam relativas a bacia Amazônica a primeira seria um canal entre a Bacia do Orinoco e o rio Negro na Bacia do Amazônas e a segunda seria um canal entre o rio Cuiabá na Bacia do Prata e Arinos na Amazônica. A realização de tais obras dariam uma gigantesca centralidade à Bacia Amazônica dentro do continente, permitindo o transporte fluvial de cargas desde Buenos Aires ao Caribe e reforçando o poder centrípeto de nossa Bacia.

Desta forma, Travassos surge como precursor do pensamento geopolítico sobre a Amazônia trazendo conceitos primordiais como sua capacidade de integração continental centrípeta, da ameaça externa e da busca de recursos na região. Ademais, a região se projeta através da hidrografia para três regiões fundamentais: o Altiplano boliviano, os "Nudos" peruanos para o Pacífico e o Orinoco para o Caribe. O livro "Projeção Continental do Brasil"é uma das primeiras obras a propor tanto a integração nacional quanto internacional da bacia amazônica pelo protagonismo brasileiro de forma a garantir sua segurança frente a ameaças externas. (TRAVASSOS, 1935) 


\section{General Golbery do Couto e Silva}

O autor seguinte a ser abordado é o general Golbery do Couto e Silva que sistematiza o modo de avançar o desenvolvimento para os interiores do Brasil. Golbery além de ser um pensador geopolítico atuou durante anos como parte do governo, tendo acesso para expor e implementar suas ideias.

Ao olhar para o espaço nacional, Golbery identifica três zonas no país : 0 ecúmeno central, composto pelo triângulo Rio de Janeiro - São Paulo - Brasília, região esta que reúne as principais indústrias, infraestrutura e população; três áreas peninsulares ao ecúmeno que são o nordeste, sul e centro-oeste, regiões que tem algum dinamismo; e, por fim, a ilha amazônica isolada do restante do país. Neste contexto, Golbery compara o país a um arquipélago em que várias ilhas de progresso são separadas por vácuos de conexões e infraestrutura, as chamadas "fronteiras ocas".

(...) é preciso que não esqueçamos o vácuo de poder, como centro de baixas pressões, atrai de todos os quadrantes os ventos desenfreados da cobiça. E, portanto, se larga é empresa e sobremodo difícil, impõe-se pelo menos dispor de sem tardança, na cintura dessa imensa área vazia, postos avançados de nossa civilização, convenientemente equipados para que possam testemunhar a posse indiscutível da terra, à espera dos melhores dias de uma integração e valorização continua e totais, e estejam em condições de opor-se a quaisquer veleidades alienígenas de penetração. (COUTO e SILVA, 1981, p.43)

Para que seus objetivos estratégicos sejam alcançados, Golbery estipulou três momentos para que o avanço da infraestrutura continuasse. Primeiro em que é imperativo articular a base ecumênica as penínsulas do nordeste e sul e ao mesmo tempo "tamponar" as vias interiores de penetração, especialmente na ilha Amazônica. O termo "tamponar" a que ele se refere, e que será mais explorado à frente, é a ocupação de áreas estratégicas por meio de ações de desenvolvimento pontuais. Em seguida, avançar para o centro-oeste a partir das áreas já integradas. Por fim, integrar a "Hiléia" Amazônica por bases avançadas no centro-oeste e através do curso do rio Amazonas no sentido leste-oeste. 


\section{Universidade Federal Fluminense Instituto de Estudos Estratégicos}

Ademais, Golbery adverte que apesar do Brasil ter uma população jovem e em elevado crescimento, ainda deveria resolver problemas sociais como o êxodo dos campos, o déficit educacional entre o campo e as cidades e a falta de diversidade econômica.(COUTO e SILVA, 1981) Tais questões demonstram uma simultânea preocupação tanto nos aspectos econômicos quanto sociais do Estado e que para galgar a questão estratégica esses dois fatores teriam de ser trabalhados em conjunto.

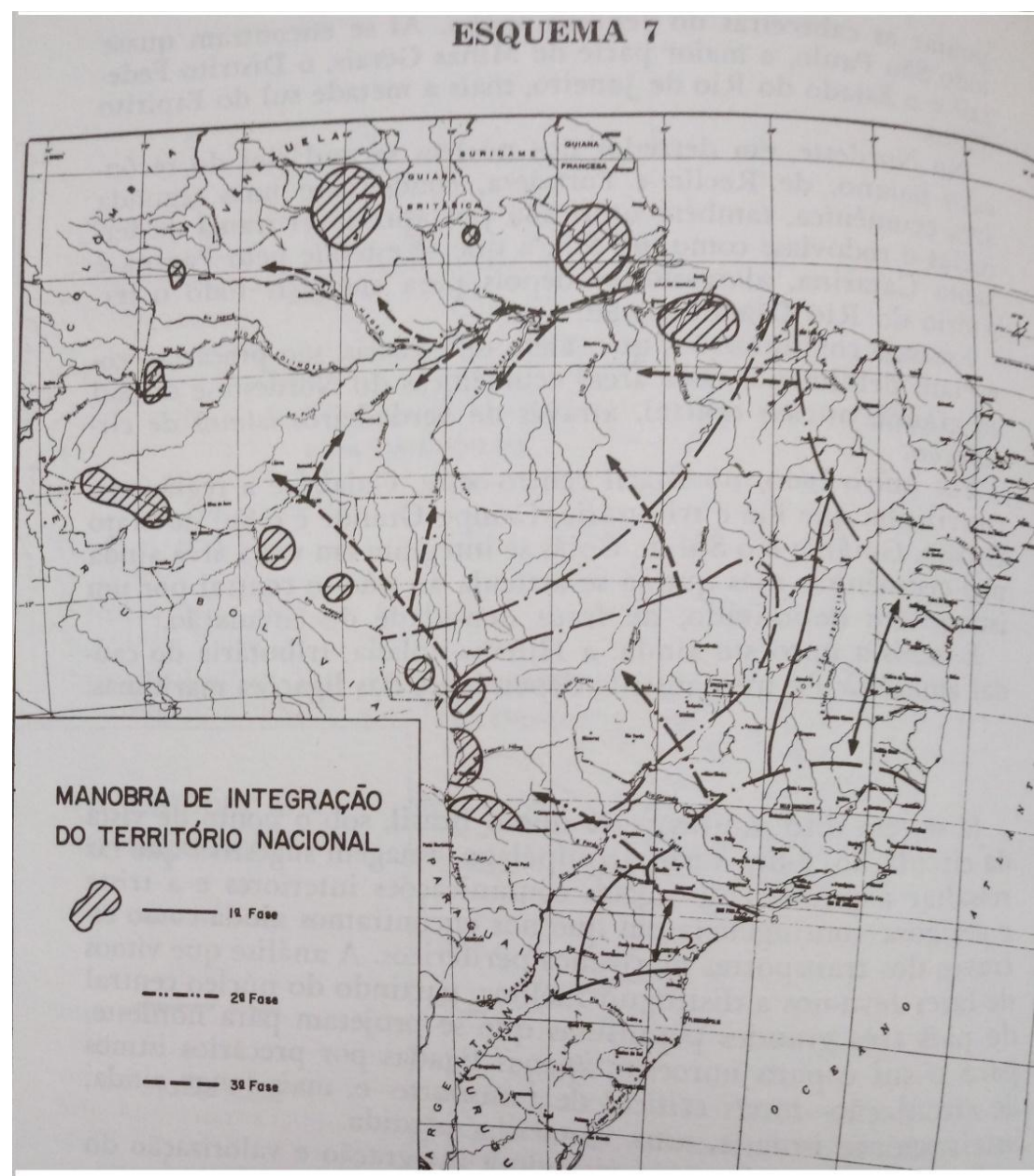

\section{Mapa 2 - Manobra de Integração do Território Nacional Fonte: (COUTO e SILVA, 1981, p.46).}

Em sua origem, Golbery inspirado em Everardo Backheuser, também um geopolítico do exército, que fala das "leis de cultura". Neste autor pode-se encontrar muito do que seria a base do pensamento de Golbery, onde a civilização brasileira partiria de seu ecúmeno no Sudeste em direção ao interior 
e eventualmente a Amazônia. Mais profundamente sobre as leis, a primeira versa acerca da dilatação de um dado ecúmeno por função do seu grau de cultura, ou seja, sua expansão para zonas menos desenvoltas; a segunda acerca de uma posição geográfica optimum variar de acordo com sua cultura e a terceira que as civilizações tendem a retornar ao Equador (sua origem) (FREITAS, 2004, p.15). As duas últimas leis colocam o Brasil com seu vasto território amazônico em uma posição privilegiada para alcançar seu potencial ao satisfazer a expansão civilizacional do Brasil do Sudeste para os trópicos na Amazônia, onde se chegaria ao optimum. Golbery enxerga neste potencial a possibilidade do Brasil se lançar como potência e formula sua estratégia por fases.

Em sua visão, Golbery busca valorizar o território nacional, a época ainda mal ocupado e com o dinamismo econômico concentrado em seu ecúmeno. No que se refere à Amazônia, a região conta com infraestrutura muito precária sem integração ao restante do país e com fronteiras desocupadas, constituindo assim uma porta de entrada para qualquer um. No entanto, Golbery encontra historicamente a preocupação na colonização e proteção da região, especialmente, nas fronteiras.

Aí estão a nos testemunhar a política previdente de nossos avós. o Forte Príncipe da Beira no Guaporé, Tabatinga no Amazonas, Marabitanas no Rio Negro, e São Joaquim no Rio Branco. O que urge fazer em outra escala e com outros meios, é ainda a mesma idéia velha em circunstâncias novas. É preciso tamponar o deserto (COUTO e SILVA, 1981, p.43)

Tal fato, entretanto, foi um forte ponto de tensão entre o Brasil e seus vizinhos. Esses pensamentos foram vistos como imperialistas por muitos e a alta posição de Golbery no governo apenas afirmava tais preocupações. Tal linha de pensamento semelhante ao Destino Manifesto em pouco servia para ações coordenadas, mas para Golbery o puro potencial realizado do Brasil já seria o suficiente ante o cinturão hispanico. (Kelly, 1997)

Para realizar este feito, Golbery projeta já em uma primeira fase de seu projeto a necessidade de ocupar os pontos de acesso fronteiriços ao interior do Brasil. Ainda neste ponto é ressaltada a urgência de se criar rodovias, ferrovias 


\section{Universidade Federal Fluminense Instituto de Estudos Estratégicos}

e de se revitalizar os portos marítimos e fluviais; que no momento se encontravam abandonados, com portos assoreados e administração portuária caótica. Já durante a segunda fase que objetivava a criação de uma "cabeça de ponte" ou base avançada para adentrar a floresta amazônica, sendo seguida pela terceira fase que "inundaria de civilização" a hiléia. Golbery vê a utilização do rio Amazonas como uma ferramenta fundamental para esta expansão, valendo-se da direção leste oeste do rio, este serviria como estrada principal para este projeto. Sendo ao sul amparado pela infraestrutura construída no centro-oeste. (COUTO e SILVA, 1981)

Esta fórmula que Golbery utiliza para construção de uma estratégia de integração nacional coloca a questão amazônica como foco principal. Toda a corrida de integração que deve ser promovida pelo Brasil objetiva, primeiramente, segurar e em seguida integrar fisicamente o território amazônico; em um movimento concêntrico do ecúmeno sudeste passando pelo centrooeste. Entretanto, a região não constitui apenas uma vulnerabilidade externa por conta de seu baixo aproveitamento, mas uma oportunidade que deve ser usada em prol do desenvolvimento nacional brasileiro. (COUTO e SILVA, 1981)

Relativo a possíveis ameaças externas, ao contrário de Travassos, Golbery identifica não uma ameaça direta ao Brasil pelos Estados Unidos. Mas sim uma ameaça indireta aos Estados Unidos que consequentemente afetaria o Brasil. Golbery enxerga na ampla geopolítica da Guerra Fria a posição privilegiada do estuário do Amazonas e costa nordestina, pontos estratégicos no trânsito do Atlântico Sul e a oportunidade de utilizá-las como moedas de troca. Nas palavras de Golbery o Brasil deve se valer desse "monopólio" sobre o Atlântico Sul e estar "... dispostos a utilizá-lo em benefício de nossos irmãos do norte, a que nos ligam tantos e tão tradicionais laços de amizade e de interesses, e em defesa ao mesmo tempo da civilização cristã, que é nossa, contra o imperialismo comunista de origem exótica" (COUTO e SILVA, 1981, p.52).

Com isso Golbery espera que os Estados Unidos reconheçam o "Destino Manifesto" do Brasil para a região, assim como o Reino Unido reconheceu no passado o "Destino" norte americano para o ocidente e soube ceder, o que faltaria para Golbery é apenas o "(...) o conhecimento, por parte dos dinâmicos 
criadores da grandeza norte-americana, de que exista de nosso lado uma vontade decidida de aceitar plenamente as responsabilidades que nos cabem, impulsionando uma positiva capacidade realizadora." (COUTO e SILVA, 1981, p.52-53)

Ainda sobre as vulnerabilidades externas, Golbery não enxerga a colonização estrangeira da Amazônia por recursos naturais como uma possível fonte de cobiça do exterior. Para ele o continente africano permaneceria muito mais visado por ter maior dificuldade em se "rebelar" e por não estar protegido por um fosso oceânico como o Atlântico Sul. Para Golbery, o Brasil deve participar da vanguarda da civilização ocidental e se utilizar de sua posição e recursos na estratégia da Guerra Fria, sempre que possível obtendo recompensas por sua participação. Mesmo assim sua mensagem de integração, valorização e expansionismo para o interior do território nacional configuram um forte ímpeto para a reorganização e incorporação da hiléia amazônica as dinâmicas econômicas que se desenvolviam no território brasileiro.(COUTO e SILVA, 1981)

Enquanto, Travassos vê a Amazônia como ponto focal no continente americano, para a projeção do Brasil. Golbery a insere dentro de um projeto de desenvolvimento nacional mais amplo vindo do ecúmeno pelas penínsulas. Relativo a Bacia, ambos encontraram poder em sua utilização, mas Golbery irá prezar por cobrir de forma mais imediata pontos vulneráveis na fronteira antes de prosseguir em sua terceira fase de "inundação de civilização". Ademais, em seu momento o Brasil já ultrapassava a Argentina o que tornava a menos "antagônica". Logo a projeção continental do Brasil para seus vizinhos seria uma consequência posterior de seu desenvolvimento e da anuência americana.

Desta maneira, ao se fazer a comparação entre Golbery e Travassos sobre suas visões com relação aos Estados Unidos, encontramos uma forte discordância. Como já visto anteriormente, Travassos via a atuação americana na América do Sul como algo preocupante e que deveria ser contrabalanceado pelo Brasil apesar da desproporcionalidade de forças, sendo os recursos naturais fontes de preocupação. Já Golbery por outro lado via que por conta de uma "ameaça comum" soviética, um "destino" brasileiro sobre a América do Sul, 


\section{Universidade Federal Fluminense Instituto de Estudos Estratégicos}

que os Estados Unidos cederiam ao Brasil a liderança na região, desde que esta não afetasse o caribe. Ademais, o Brasil de Golbery é parte de uma estratégia não mais apenas continental, mas global em um contexto histórico de bipolaridade. Quanto à obtenção de matérias primas, a África permaneceria como fonte principal o que ajudaria a afastar a cobiça estrangeira dos recursos presentes na Amazônia. (COUTO e SILVA, 1981) (TRAVASSOS, 1935)

\section{General Carlos de Meira Mattos}

Trazendo grandes contribuições ao estudo da geopolítica amazônica, o general Carlos Meira Mattos aprofunda a reflexão sobre a floresta introduzindo o conceito de Pan-Amazônia. Este conceito deixa de ver a floresta como algo restrito ao território nacional brasileiro, mas como parte de um grande sistema que integra vários países por um vasto sistema de rios tributários ao Amazonas, de ecologia e relevo uniformes. Desta forma, a análise das partes em separado não representaria o verdadeiro valor e importância do todo.(MATTOS, 1980)

\footnotetext{
As palavras amazônia e pan-amazônia deveriam simbolizar a mesma imagem geográfica. Na realidade isso não acontece. Esta imensa região natural, portadora de ecologia uniforme, abrangendo o território de seis países tributários, é enfocada por seus condôminos sob uma visão particularizada. Assim é quando o brasileiro ou o venezuelano, colombiano, peruano, equatoriano ou boliviano refere-se à Amazônia está falando na sua Amazônia nacional. Visando a clareza das idéias, conceitos, formulações e perspectivas deste estudo, utilizamos o vocábulo Pan-Amazônia toda vez que nos referirmos ao conjunto desta região abrangente. (MATTOS, 1980, p.22)
}

Assim como os outros autores, Meira Mattos busca levar a civilização à Amazônia que ainda era na época ainda sensivelmente isolada, pauperizada, com baixo desenvolvimento econômico e baixíssima densidade populacional. Por isso, o imperativo político de levar o desenvolvimento à região era de primeira necessidade. Entretanto, Meira Mattos traz a possibilidade de ter este desenvolvimento socioeconômico por meio de uma comunidade de nações que enfrentam desafios sócio-geográficos similares, para o autor seria apenas uma repetição de políticas anteriormente adotadas pela Europa Ocidental. 
(...) uma solução comunitária para os problemas econômicos e sociais da Pan-Amazônia levaria a vantagem de permitir um equacionamento ajustado à ecologia e às necessidades regionais. Seria uma solução amazônica para problemas amazônicos. Seria uma tentativa de vertebrar a região como um todo e não como seções secundárias de áreas marítimas do Atlântico e do Pacífico. Os benefícios colhidos se difundiriam às áreas adjacentes da Bacia do Orenoco e das Guianas onde existem carências semelhantes às da Bacia do RioMar.(MATTOS, 1980, p.146)

Meira Mattos é bastante enfático na necessidade de uma ação conjunta desses países sobre a região para que estas deixem de ser apenas áreas adjacentes. De forma ainda mais significativa diz que o impulso a esta comunidade amazônica deve ser interno e independente, seja dos Estados Unidos ou da Europa, em suas palavras: "... seremos nós, os donos do problema. Unir-nos em termos de comunidade para impulsionar o desenvolvimento regional não é novidade nem fere a sensibilidade das soberanias nacionais." (MATTOS, 1980, p.146)

Outro ponto central para Meira Mattos é a integração física por meio de infraestrutura. Primeiramente, na região amazônica o modal principal de transporte eram os rios. Esta, no entanto, causa uma série de problemas oriundos da geografia e dos ciclos naturais como as marés e quedas d'água que interrompem o percurso. Além disso, por conta de serem rotas predeterminadas várias áreas acabavam desprovidas de acesso. Por conta disso eles necessitariam sofrer intervenções para aumentar sua navegabilidade, mas ainda assim não mudariam suas posições geograficamente dadas e seus interiores permaneceriam isolados.

A vertebração do território deveria, então, ocorrer ligando o sul ao norte pelos "espigões" que se formam entre os afluentes do Amazonas daí surgiriam estradas como a Belém-Brasília, Cuiabá-Santarém e Porto Velho-Manaus; devendo em seguida articula-as horizontalmente pela Transamazônica ao sul e futuramente a Perimetral Norte ao norte do Amazonas. Estas obras além de aumentar o dinamismo no interior do Brasil, também seriam inestimáveis para integrar a Amazônia brasileira com as "Amazônias" dos países vizinhos. Para 


\section{Universidade Federal Fluminense Instituto de Estudos Estratégicos}

isto, Meira Mattos divide em três zonas de entrada ou "Áreas interiores de intercâmbio fronteiriço" em que estas obras de infraestrutura serão pivôs na articulação territorial.

A primeira área a se considerar é "frente atlântica" que segue o curso do rio Amazonas. Das três, esta é a mais desenvolvida contando com dois pontos de apoio logístico: Belém e Manaus. Para frente atlântica a infraestrutura de deslocamento é o próprio rio que permite o tráfego de navios de grande porte do oceano até lquitos no Peru. A área seguinte é a "frente do planalto" que se configura como a banda ao sul do rio Amazonas. Esta área a partir dos anos 1960 teve um alto nível de investimento em sua infraestrutura, contando com as anteriormente mencionadas vias norte-sul com seus pontos de apoio no centrooeste, assim como uma grande via leste-oeste, a Transamazônica, que permite a articulação de todas. Esta frente possibilita a articulação do Brasil com o norte da Bolívia nas cidades de Riberalta, Cojiba e Trinidad. Por fim, o arco fronteiriço que segue na banda ao norte do rio Amazonas. Esta área não possui sistemas de estradas nem pontos de apoio, sendo a Perimetral Norte sua futura via de articulação. Esta área deveria vertebrar o norte do Brasil com a Venezuela, Colômbia e Guiana.(MATTOS, 1980) 


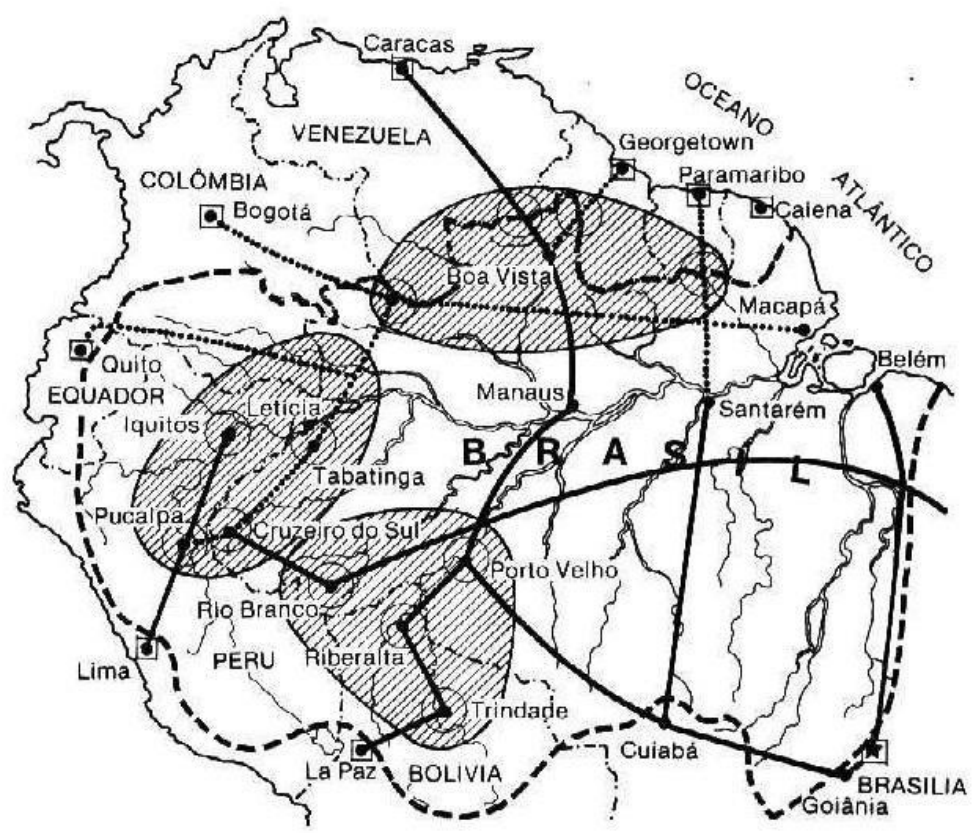

Mapa 3 - Áreas Interiores de Intercâmbio Fronteiriço

Fonte: (MATTOS, 1980, p.154).

Para Meira Mattos, estas três zonas articuladoras têm uma função fundamental no desenvolvimento da Pan-Amazônia e de um processo de integração sub-regional. Neste esquema obras de infraestrutura de transporte, comunicação e produção seriam prioridade máximas, tendo efeitos dinamizadores que se espalhariam pelas zonas vizinhas como o Orinoco e a Guiana. Neste sentido o Brasil tem papel central como locomotiva em atrair seus vizinhos não apenas para o desenvolvimento da infraestrutura, mas para todo este concerto regional de países amazônicos. Afinal o país além de seu poderio econômico, também contaria com a benesse geopolítica em controlar o centro da floresta e de sua Bacia hidrográfica. Tal ponto coloca Meira Mattos retomando o conceito da força centrípeta da Bacia já trazida por Travassos em 1935.

De forma complementar, conforme Darc Costa, os Estados Nacionais jamais deixam a possibilidade de performar uma intervenção no meio de forma a estruturar, sendo subordinadas aos determinantes de tempo e espaço. "... toda a intervenção se estrutura em um determinado espaço e tempo. Ela é uma ação em busca de um fim a ser atingido, e para isso precisa-se dispor de meios meios e fins são seus instrumentos básicos" (COSTA, 2009, p.429). 


\section{Universidade Federal Fluminense Instituto de Estudos Estratégicos}

Ademais, ele complementa Meira Mattos a visão de urgência em agregar esta zona ao espectro nacional deve-se levar em conta toda a fragilidade da infraestrutura da região que ainda hoje permanece aquém para tão vasto território. Para Costa, a questão da infraestrutura é intrinsecamente e indissociavelmente nacional em todos os seus aspectos, desde de seu planejamento dentro de um projeto nacional até sua articulação no plano nacional mais amplo e mesmo internacional (COSTA, 2009). Darc Costa, entretanto, é sóbrio no tocante ao contexto brasileiro e sem o qual a integração regional do território amazônico se torna mais difícil para os países menores fato que Meira Mattos soluciona ao tê-los junto ao brasil na busca de soluções comuns.

Dentre os pensadores da geopolítica amazônica é constante a urgência em articular este espaço de atraso sócio-econômico ao restante do país. Apesar das décadas entre Travassos e seus colegas, o controle sobre a imensidão amazônica permanece um objetivo a ser alcançado pelo Brasil, ante os interesses de potências internacionais. Como demonstram os autores, a região é central nas disputas tanto na América do Sul quanto no Atlântico Sul, além de ter um vasto depósito de recursos naturais a serem explorados. A seu favor o Brasil tem uma posição privilegiada, controlando o curso principal do rio Amazonas, além de por meio de suas riquezas ter feito grandes obras de infraestrutura que aumentam ainda mais seu poder de penetração sobre a região. Entretanto, a integração com seus vizinhos ainda está aquém do necessário e falta interesse do Brasil em se colocar como articulador entre os países da Pan-Amazônia.(MATTOS, 1980)

Meira Mattos, retoma muito do pensamento de Travassos, mas o desenvolvem em uma inserção conjugada em interesses comuns. A integração não mais ocorreria ante uma disputa regional ou internacional, mas com o objetivo de alcançar um desenvolvimento conjunto contra uma natureza similar. Tal fato garantiria maior aplicabilidade às soluções que serviriam a múltiplas nações diminuindo seu custo de desenvolvimento e implementação. Enquanto Travassos vê na Amazônia uma zona de disputas entre rivais, Meira Mattos enxerga parceiros. 
Por outro lado, Meira Mattos, passa por algumas divergências com seu contemporâneo Golbery. Apesar de menos sistemático em sua análise do que Golbery, Meira Mattos busca uma inserção mais autônoma do Brasil no cenário internacional, sem esperar benesses. Ademais, a inserção colaborativa no espaço Amazônico garantiria ao Brasil um entorno mais amistoso e menos desconfiado do que aquele proposto por Golbery. Nesse sentido, o Brasil não se lançaria como o novo imperialista ou subimperialista, mas como um parceiro de interesses em comum.

Unlike the Machiavellian image of General Golbery do Couto e Silva of Brazil, whose works we will examine shortly, Meira Mattos is recognized as a champion of Brazilian development and integration. His vision reflects a positive and nonbelligerent purpose in regional politics, according to Argentinean Nicolás Boscovich (1986: 40 41). To the general, Brazil merits international recognition because of its regional leadership, not its power, and he wants to promote continental development as well as heighten Brazil's security and prosperity through an amicable geopolitical model (1984b; 1982; 1980b; 1979). (Kelly, 1997)

Golbery e Meira Mattos, entretanto, ainda compartilham certas semelhanças que valem nota. Ambos foram ávidos leitores do historiador Arnold Toynbee, que desenvolveu a famosa tese do desafio resposta. Toynbee encontra um padrão na Gênese das civilizações, em que um povo é desafiado e deve em resposta mostrar sua criatividade e resiliência. Este desafio é dado pela natureza e se apresenta de forma particular em cada local, e quando um povo é capaz de superar tal desafio ele é alçado a um patamar maior no mundo. Este conceito é de extrema importância tanto para Meira Mattos quanto para Golbery. Ambos veem a Amazônia como o desafio a ser respondido pela civilização brasileira. Assim, dada a altura do desafio imposta pela Amazônia, o patamar a ser alcançado pelo Brasil também seria impar no mundo.

Por fim, ambos, Meira Mattos e Golbery em especial tiveram papel fundamental nos programas de desenvolvimento da região como o Calha Norte, Projeto Rondon, SIVAM, dentre outros. Ambos militares tiveram acesso privilegiado aos conselhos estratégicos para formar as políticas de infraestrutura e integração, tendo Golbery inclusive integrado a Casa Civil durante o governo 
Geisel. Este fator os coloca na situação não apenas de pensar mas de terem tido a oportunidade de implementar suas ideias.

\section{Conclusão}

Após o percurso por nossos três autores, vemos como a dinâmica da Amazônia se alterou e passou por diferentes perspectivas e preocupações. Para Travassos tínhamos uma rivalidade a ser superada, para Golbery um Destino Manifesto de direito e Meira Mattos vizinhos com problemas e soluções em comum que deveriam se ajudar. Entretanto, um grave problema perpassa a todos que é a necessidade de integrar e desenvolver a Amazônia, e todos têm a partir da visão geopolítica o olhar de como agir.

O Brasil sendo o país equatorial mais desenvolvido de fato tem a melhor chance de solucionar as questões e desafios impostos pela floresta. O rio Amazonas e seus afluentes representam uma casualidade geográfica muito singular que se estende em todas as direções de um vasto interior, tendo um alto calado e proximidade com outros sistemas hidrográficos de alta vazão. A geografia que por tantas vezes inibe ou proíbe se apresenta no Amazonas em uma dadiva.

\section{Bibliografia}

CORPORACIÓN ANDINA DE FOMENTO. Los ríos nos unen. Santa Fé de Bogotá, Editora Guadalupe LTDA, 1998.

COSTA, D. Estratégia Nacional, A cooperação Sul-Americana como caminho para a inserção internacional do Brasil. Rio de Janeiro: COPPE, 2003

COSTA, D. Fundamentos para o Estudo da Estratégia Nacional. São Paulo: Editora Paz e Terra, 2009

COUTO E SILVA, Golbery. Geopolítica do Brasil. Rio de Janeiro, Editora José Olympio, 1981.

FREITAS, J. M. C.A Escola Geopolítica Brasileira. Rio de Janeiro: Editora do Exercito, 2004. 
KELLY, P. Checkerbords and Shatterbelts. Austin, Editora University of Texas Press, 1997.

MATTOS, C. M. Uma Geopolítica Pan-Amazônica. Rio de Janeiro: Editora José Olympio, 1980.

TRAVASSOS, M. Projeção Continental do Brasil. São Paulo: Companhia Editora Nacional, 1935. 